\title{
Calibration of a generalized plasticity model for compacted silty sand under constant-suction shearing tests
}

\author{
Marcos García-García ${ }^{1}$, Ujwalkumar D. Patil ${ }^{2}$, Diego Manzanal ${ }^{1, *}$, Laureano R. Hoyos ${ }^{3}$, Anand J. Puppala ${ }^{4}$, Manuel \\ Pastor $^{5}$ \\ ${ }^{1}$ Department of Continuum Mechanics and Theory of Structures. ETSICCyP, Universidad Politécnica de Madrid, Spain \\ ${ }^{2}$ School of Engineering, University of Guam, UOG Station, Mangilao, GU 96923, USA \\ ${ }^{3}$ Department of Civil and Environmental Engineering University of Texas at Arlington, Texas 76019, USA \\ ${ }^{4}$ Department of Civil and Environmental Engineering, Texas A \& M University, College Station, Texas, 77843, USA \\ ${ }^{5}$ Department of Applied Mathematics in Engineering, ETSICCyP, Universidad Politécnica de Madrid, Spain
}

\begin{abstract}
The stress-strain response of compacted silty sand with over-consolidated stress history often exhibit distinct peak stress before reaching the critical stress type of response when subjected to suctioncontrolled triaxial shearing. Such heavily consolidated soil also tends to simultaneously manifest initial compression which transitions into dilational type volumetric response. Modelling such strain-softening type response, especially emulating the smooth transition from peak to critical state is a challenge. In this paper a previously developed generalized plasticity constitutive model, called MPZ (Modified PastorZienkiewicz) is fine-tuned and calibrated using a set of suction-controlled consolidated drained triaxial tests conducted on compacted silty sand specimens. Firstly, the saturated and unsaturated silty sand characteristics and the experimental test program are briefly introduced. Secondly, the calibration of each component of the constitutive model, namely critical state, dilatancy, peak state, loading direction, water retention curve and bounding function are briefly explained. Furthermore, the material parameters are estimated, model performance is displayed, and finally discussed. Preliminary simulations show that the MPZ model is able to mimic overall suction controlled triaxial test response of compacted silty sand decently well by taking into account the changes in density, pressure and suction. However, the peak states are not accurately modelled for low-high suction levels which needs further modifications in proposed model.
\end{abstract}

\section{Introduction}

Typically, the compacted soils remain in unsaturated condition almost throughout the year and hence suction plays a key role in obtaining the unsaturated soil response. Experimental characterization of the compacted soil over wide range of soil suction and external confining stress assists us in the assessment of our current unsaturated soil shear strength evaluation protocols, expand our database of strength and volume change response for various soils, and understand to the furthest extent the macro-level interaction between solid grains and air-water menisci. Although, the experimental results form a necessary basis to validate the predicted response from a particular soil model, there is a further need to reinforce the same from more than one constitutive modelling approach. For more than three decades now several researchers have spent considerable efforts in either developing new constitutive models or have tried modifying existing models to predict the unsaturated soil response. Most notably, among them being the Barcelona Basic Model, BBM [1], and
Bounding Surface Plasticity theory-based models $[2,3,4,5,6]$. BBM has been widely used in simulating the response of normally consolidated and slightly over consolidated unsaturated soils but it fails to capture the post peak softening and stress induced dilatancy response which is typical of over consolidated soils.

Compacted silty sand specimens with over consolidated stress history exhibit different response when compared with response of same soil but with normally consolidated stress history at varying suction [7]. Normally consolidated soils show continuous strain hardening type stress-strain response followed by compression type volumetric response. On the other hand, the over consolidated soils tend to show post-peak softening type stress-strain response accompanied by initial compression followed by dilation type volumetric response. Accommodating these two distinct and different types of stress-strain and volume change response in soil-models is a challenge for researchers. Pastor, Zienkiewicz and Chan [8] proposed a generalized plasticity model for saturated soils which was later

Corresponding author: d.manzanal@upm.es 
modified by Manzanal et al. [9] and also later extended to unsaturated soils [10].

In this paper, a generalized plasticity model, named MPZ (Modified Pastor-Zienkiewicz) [8,10], capable of reproducing unsaturated states is used to reproduce the response of suction-controlled consolidated drained triaxial experimental tests conducted by [7]. The formulation of MPZ model and physical properties including saturated and unsaturated properties of test soil along with test procedure are briefly explained. Calibration of the important features of the MPZ model in light of recently obtained experimental test results is then outlined. A discussion of the model performance is then presented.. Preliminary model simulations from present studies demonstrate ability of proposed MPZ model to account for the influence of capillary forces and external confining stress on the stress-strain and volume change response, and therefore, validates its ability to reproduce the macro mechanical behaviours of unsaturated test materials.

\section{Soil properties and test methods}

\subsection{Soil properties}

The test soil is classified as silty sand (SM) according to the Unified Soil Classification System (USCS). The physical and unsaturated properties of the compacted silty sand are listed in Table 1. Each soil sample was prepared by statically compacting it in a steel mold in nine equal layers (stress-based compaction) at a moisture content of $+2 \%$ of optimum moisture content and at its maximum proctor dry density. Care was taken to produce almost identical soil samples with similar dimensions and initial compacted properties for each test. More details can be obtained from Patil et al. [10].

Table 1. Properties of compacted silty sand specimens.

\begin{tabular}{|l|l|}
\hline Diameter & $71.12 \mathrm{~mm}$ \\
\hline Height & $142.24 \mathrm{~mm}$ \\
\hline Specific gravity $\left(\mathrm{G}_{\mathrm{s}}\right)$ & 2.67 \\
\hline Dry specific weight $\left(\gamma_{\mathrm{d}}\right)$ & $17.65 \mathrm{kN} / \mathrm{m}^{3}$ \\
\hline Initial voids ratio $(\mathrm{e})$ & $0.46-0.49$ \\
\hline Initial degree of saturation $(\mathrm{S})$ & $77-82 \%$ \\
\hline Air Entry Value & $8-10 \mathrm{kPa}$ \\
\hline Method of compaction & Static \\
\hline
\end{tabular}

\subsection{Suction-controlled triaxial testing program}

Fig.1. shows the actual photograph of the double-walled triaxial equipment modified to accommodate the unsaturated soil testing that was used in conducting a series of suction-controlled consolidated drained triaxial tests following conventional triaxial compression (CTC) stress path. Saturated triaxial tests were conducted at three confining stresses i.e., $\sigma_{3}=100,200$ and $300 \mathrm{kPa}$. For unsaturated testing, after preparing the soil sample, it was carefully transferred to the triaxial cell and the target suction-equalization was achieved within the triaxial cell via axis-translation technique. After the pore-fluid equalization stage, isotropic consolidation under constant matric suction ending with net confining stress $\left(\mathrm{p}=\sigma_{3}-\mathrm{u}_{\mathrm{a}}\right)$ of 100,200 and $300 \mathrm{kPa}$ is accomplished. As the suction is kept constant, cell pressure $\left(\sigma_{3}\right)$ is increased to attain the target net stress. Once the sample has fully dissipated the excess of pore-air and pore-water pressures, the suction-controlled shearing phase is carried out. Both matric suction and net stress are constant throughout the strain-controlled shearing stage.

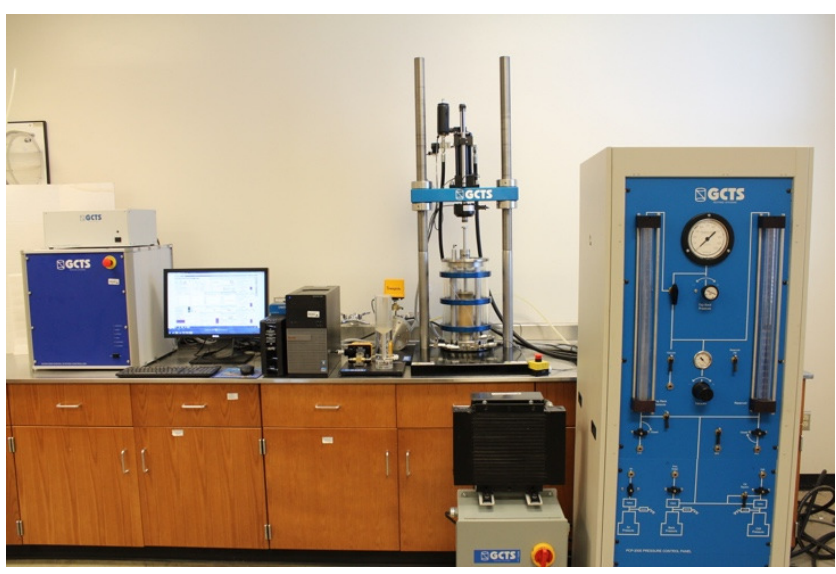

Fig. 1. Panoramic view of actual double walled-triaxial test setup modified to test unsaturated soil.

Table 2 includes void ratio and water content at the end of compaction (initial) and shearing (final) phases. It is an extract from Table 1 of [7], omitting equalization (II) and consolidation (III) stages. In this paper the notations adopted for the test values are "p"-"s", where $p$ is net stress and $s$ is the suction.

Table 2. Void ratio and water content from experimental program.

\begin{tabular}{|c|c|c|c|c|}
\hline \multirow{2}{*}{$\begin{array}{c}\text { Test } \\
(\mathrm{CD})\end{array}$} & \multicolumn{2}{|c|}{ Initial } & \multicolumn{2}{c|}{ Final } \\
\cline { 2 - 5 } & $\mathrm{e}(-)$ & $\mathrm{w}(\%)$ & $\mathrm{e}(-)$ & $\begin{array}{c}\mathrm{w} \\
(\%)\end{array}$ \\
\hline $100-0$ & 0.659 & 14.2 & 0.539 & 15.8 \\
\hline $200-0$ & 0.504 & 14.2 & 0.383 & 16.9 \\
\hline $300-0$ & 0.499 & 14.2 & 0.341 & 17.4 \\
\hline $100-50$ & 0.659 & 14.2 & 0.483 & 11.5 \\
\hline $200-50$ & 0.504 & 14.2 & 0.492 & 8.5 \\
\hline $300-50$ & 0.499 & 14.2 & 0.500 & 6.5 \\
\hline $100-250$ & 0.659 & 14.2 & 0.493 & 3.3 \\
\hline $200-250$ & 0.504 & 14.2 & 0.453 & 10.8 \\
\hline $300-250$ & 0.499 & 14.2 & 0.471 & 8.6 \\
\hline $100-500$ & 0.659 & 14.2 & 0.472 & 6.7 \\
\hline $200-500$ & 0.504 & 14.2 & 0.474 & 3.2 \\
\hline $300-500$ & 0.499 & 14.2 & 0.466 & 10.8 \\
\hline $100-750$ & 0.659 & 14.2 & 0.445 & 9.8 \\
\hline $200-750$ & 0.504 & 14.2 & 0.435 & 5.1 \\
\hline $300-750$ & 0.499 & 14.2 & 0.457 & 3.1 \\
\hline
\end{tabular}

Compacted specimens were tested in unsaturated condition at four matric suction values (i.e., $\mathrm{s}=50,250$, 500 , and $750 \mathrm{kPa}$ ) and at three values of net confining 
stress i.e., $\sigma_{3}-\mathrm{u}_{\mathrm{a}}=100,200$ and $300 \mathrm{kPa}$. Both sample preparation and experimental program, including porefluid equalization and preconditioning stages, are thoroughly described in [7].

\section{Generalized plasticity model}

\subsection{Constitutive model framework}

Generalized plasticity (GP) constitutive models are characterised by introducing the phenomenological features in a hierarchical manner, i.e., progressing from simple to complex models, acquiring generality as they are further developed. In this context, first generalized plasticity models were used in the late 1980's and 1990's [8]. They were further improved to account for anisotropy [11], stress history [12], critical state [9] and unsaturated state [10].

\subsubsection{Formulation}

The present constitutive model is based on a formulation that reproduces the main features of unsaturated soil behaviour. Both these features and their corresponding equations are subsequently summarized, beginning with the saturated framework and continuing with the extension to unsaturated soils. Formulae references can be traced back in [9] and [10].

Critical state line (CSL) depends on both pressure and density level as shown in Eq. (1).

$$
e_{\mathrm{c}}=e_{\mathrm{a}}-\lambda \cdot\left(p^{\prime} / p_{\mathrm{a}}{ }^{\prime}\right)^{\zeta}
$$

where: $\mathrm{e}$ is the void ratio, $\mathrm{p}^{\prime}$ is effective mean pressure, $\lambda$ and $\zeta$ are material parameters, subindex $c$ denotes critical state and subindex $a$ denotes atmospheric values.

On the triaxial stress space, CS imposes a limit on the $\mathrm{q} / \mathrm{p}^{\prime}$ ratio as shown in Eq. (2).

$$
q_{\mathrm{c}}=M_{\mathrm{g}} \cdot p^{\prime}
$$

where $M_{\mathrm{g}}$ is a material parameter

Dilatancy, $\mathrm{d}$, is also density- (through void ratio) and stress-dependent as shown in Eq. (3).

$$
\mathrm{d}=\mathrm{d}_{0} \cdot\left(\mathrm{e}^{\mathrm{m} \psi \mathrm{s}}-\eta / M_{\mathrm{g}}\right)
$$

where: $\mathrm{d}_{0}$ and $\mathrm{m}$ are material parameters, $\eta$ is the stress ratio $\left(\mathrm{q} / \mathrm{p}^{\prime}\right)$ and $\psi_{\mathrm{s}}$ is the state parameter (Eq. 4), which measures in terms of void ratio, the gap between current and critical (c) state.

$$
\psi_{\mathrm{s}}=\mathrm{e}-\mathrm{e}_{\mathrm{c}}
$$

Elastic functions, namely $\mathrm{G}_{\mathrm{es}}$ and $\mathrm{K}_{\mathrm{ev}}$, consider density- and pressure-dependence (Eqs. 5, and 6).

$$
\begin{aligned}
& \mathrm{G}_{\mathrm{es}}=\mathrm{G}_{\mathrm{es} 0} \cdot(2 \cdot 97-\mathrm{e})^{2} /(1+\mathrm{e}) \cdot\left(\mathrm{p}^{\prime} \cdot \mathrm{p}_{0}{ }^{\prime}\right)^{1 / 2} \\
& \mathrm{~K}_{\mathrm{es}}=\mathrm{K}_{\mathrm{ev} 0} \cdot(2.97-\mathrm{e})^{2} /(1+\mathrm{e}) \cdot\left(\mathrm{p}^{\prime} \cdot \mathrm{p}_{0}\right)^{1 / 2}
\end{aligned}
$$

where: $\mathrm{G}_{\mathrm{es} 0}$ and $\mathrm{K}_{\mathrm{ev} 0}$ are material parameters and $\mathrm{p}_{0}{ }^{\prime}$ is the initial mean effective pressure. Poisson modulus, $v$, can be obtained from $\mathrm{G}_{\mathrm{es} 0}$ and $\mathrm{K}_{\mathrm{ev} 0}$ with (Eq. 7).

$$
\mathrm{K}_{\mathrm{ev} 0}=2 / 3 \cdot \mathrm{G}_{\mathrm{es} 0} \cdot(1+v) \cdot(1-2 v)
$$

Compacted soils exhibit a peak state, which in the model is related to void ratio by (Eq. 8).

$$
\eta_{p}=M_{g} \cdot e^{\left(-\beta_{v} \psi_{s, p}\right)}
$$

where: subindex $p$ denotes peak state and $\beta_{\mathrm{v}}$ is a material parameter.

Loading direction constants are defined by (Eq. 9).

$$
\mathrm{M}_{\mathrm{f}} / \mathrm{M}_{\mathrm{g}}=\mathrm{h}_{1}-\mathrm{h}_{2} \cdot \psi_{\mathrm{q}}
$$

where: $h_{1}$ and $h_{2}$ are material parameters, $M_{f}$ is the slope of the yield surface in the p'-q plane and $\psi_{\mathrm{q}}$ is a variation of the state parameter (Eq. 10), being $\beta$ a material parameter.

$$
\psi_{\mathrm{q}}=\left(\mathrm{e} / \mathrm{e}_{\mathrm{c}}\right)^{\beta}
$$

Plastic modulus $\mathrm{H}_{\mathrm{L}}$ is a function (Eq. 11) of different plastic moduli $\left(\mathrm{H}_{\mathrm{DM}}, \mathrm{H}_{\mathrm{f}}, \mathrm{H}_{\mathrm{v}}, \mathrm{H}_{\mathrm{s}}\right)$ whose formulation is presented in [2] and references therein.

$$
\left.\mathrm{H}_{\mathrm{L}}=\mathrm{H}_{0}{ }^{\prime} \cdot \mathrm{e}^{\left(--\beta_{0} \psi_{\mathrm{q}}\right.}\right)\left(\mathrm{p}^{\prime} \cdot \mathrm{p}_{0}{ }^{\prime}\right)^{1 / 2} \cdot \mathrm{H}_{\mathrm{DM}} \cdot \mathrm{H}_{\mathrm{f}} \cdot\left(\mathrm{H}_{\mathrm{v}}+\mathrm{H}_{\mathrm{s}}\right)
$$

On top of the previous formulation, following equations are needed to adapt the GP model to unsaturated states.

Effective stress, $\boldsymbol{\sigma}^{\prime}$, in unsaturated states is of the form (Eq. 12).

$$
\boldsymbol{\sigma}^{\prime}=\left(\boldsymbol{\sigma}-\mathbf{p}_{\mathrm{a}}\right)+\mathbf{s} . \mathrm{Sr}
$$

where: $\mathbf{s}=\mathbf{p}_{\mathrm{a}}-\mathbf{p}_{\mathrm{w}}$ is the matrix suction, $\mathbf{p}_{\mathrm{a}}$ is the pore air pressure, $\mathbf{p}_{\mathrm{w}}$ is the pore water pressure and $\mathrm{Sr}$ is the saturation degree. Bold face indicates tensor functions.

The water retention curve (WRC), also known as Soil Water Characteristic Curve (SWCC), (Eq. 13), relates matrix suction and saturation degree [11]. The experimental points were best-fitted with a modified Fredlund and Xing [10,13,19] model.

$$
\mathrm{S}_{\mathrm{r}}=\mathrm{S}_{\mathrm{r} 0}+\left(1-\mathrm{S}_{\mathrm{r} 0}\right)\left\{\ln \left[\mathrm{e}^{1}+\left(\mathrm{s} * / \mathrm{a}_{\mathrm{w}} \cdot \mathrm{p}_{0}\right)^{\mathrm{n}}\right]\right\}^{-\mathrm{m}}
$$

where: $S_{\mathrm{r} 0}$ is the residual degree of saturation, $\mathrm{s}^{*}=\mathrm{e}^{\Omega} . \mathrm{s}[14]$ is the normalized matrix suction and $\Omega, \mathrm{a}_{\mathrm{w}}$, $\mathrm{n}, \mathrm{m}$ are material parameters.

In order to express the influence of suction, a bonding or cementation parameter, $\xi$, is introduced, according to [15].

Thus, formulation of CSL (1) is modified by (Eq. 14), following the criterion from [16].

$$
e_{\mathrm{c}}=e_{\mathrm{a}}-\lambda \cdot\left(p^{\prime} / p_{\mathrm{a}}{ }^{\prime}\right)^{\zeta} \cdot(1+\mathrm{g}(\xi))^{-\zeta}
$$

where: $\mathrm{g}(\xi)$ is a bonding function (Eq. 15).

$$
\mathrm{g}(\xi)=a\left[e^{(b \xi)}-1\right]
$$

and $\xi$ is the bonding parameter $[15,16]$ and $a, b$ are material parameters [19]. 
Bonding function (Eq. 15) relates the values of the critical effective stress, $\mathrm{p}_{\text {cs }}$, at $\mathrm{s}=0$ (saturation) and at a given suction (Eq. 16), as introduced in [10].

$$
\mathrm{p}_{\mathrm{cs}}^{\prime \text { unsat }} / \mathrm{p}_{\mathrm{cs}}^{\prime \text { sat }}=(1+\mathrm{g}(\xi))
$$

\section{Model calibration}

As explained in section 3.1.1, the constitutive formulation of the model requires adjusting the material parameters. In the following, procedures to calibrate each component of the model will be outlined, namely: critical state, dilatancy, elasticity, peak state, loading direction and plastic modulus, along with WRC and bonding function.

\subsection{Critical state}

Critical state requires the estimation of four parameters: $\mathrm{e}_{\mathrm{a}}, \lambda, \zeta$ and $\mathrm{M}_{\mathrm{g}}$. First three are related in Eq. (1) and $\mathrm{M}_{\mathrm{g}}$ in Eq. (2). To adjust parameters of Eq. (1), void ratio (e) vs normalized pressure $\left(\mathrm{p}^{\prime} / \mathrm{pa}\right)^{\zeta}$, both at critical state, are depicted, distinguishing between suction levels. Figure 2 shows the experimental results and the estimated values of the three parameters involved. Two tests (50-300 and 250-300) have not been considered because they divert from the overall tendency. They are shown in Figure 2 as outliers.

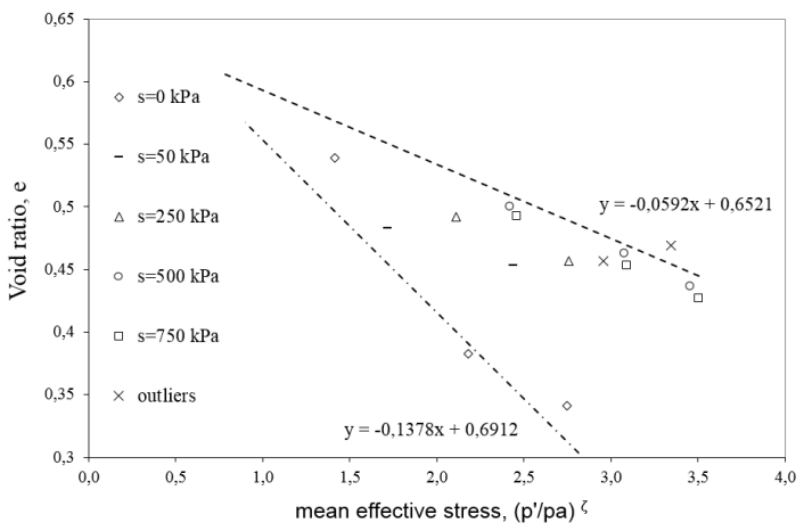

Fig. 2. Critical state line for saturated and unsaturated states.

Different parameters for saturated and unsaturated states are obtained. Values for $\mathrm{e}_{\mathrm{a}}$ and $\lambda$ have been slightly adjusted to get a more accurate model performance. Final values are indicated in Table 3.

Stress points at critical state on triaxial space (p' vs q) allow the estimation of $\mathrm{M}_{\mathrm{g}}$, where $\mathrm{p}^{\prime}$ is calculated with Eq. (12) with the residual saturation degree $S_{r}=0.05 . M_{g}$ value is referenced in Table 3 and is obtained from the saturated state.

Table 3. Critical state parameters

\begin{tabular}{|c|c|c|c|c|}
\hline Parameter & $\mathrm{e}_{\mathrm{a}}(-)$ & $\lambda(-)$ & $\zeta(-)$ & $\mathrm{M}_{\mathrm{g}}(-)$ \\
\hline Value (unit) & $0.72 *$ & $0.11 * *$ & 0.6 & 1.42 \\
\hline
\end{tabular}

$* 0.70$ for saturated samples. $* * 0.14$ for saturated samples.

\subsection{Dilatancy}

It was observed that the specimens did not dilate during saturated tests. However, all the unsaturated specimens exhibited suction-induced dilatancy. In addition, dilatancy increased with increasing suction and was supressed with increasing confinement at constant suction. Hence, dilatancy parameters need to be included in the proposed model. Dilatancy parameters are contained in Eq. (3): $\mathrm{d}_{0}$ and $\mathrm{m}$. Their estimation is done in two steps: first, $\mathrm{m}$ is determined analytically at the phase transformation point $(\mathrm{TF})$, when $\mathrm{d}=0$, as soil state changes from contractive to dilative (Table 4). Only some tests are included in the Table 4. Then, $\mathrm{d}_{0}$ is determined to fit the experimental curve "d" vs " $\psi_{\mathrm{s}, \mathrm{p}}$ " (Table 4). It is evaluated at peak state and not at the TF, because at the latter dilatancy is zero.

Table 4. Dilatancy parameter $\mathrm{m} .\left(\mathrm{M}_{\mathrm{g}}=1,42\right)$

\begin{tabular}{|c|c|c|c|c|}
\hline test & $\eta_{\mathrm{TF}}(-)$ & $\psi_{\mathrm{s}, \mathrm{TF}}(-)$ & $\mathrm{m}(-)$ & $\mathrm{d}_{0}(-)$ \\
\hline $100-50$ & 1.68 & 0.13 & 1.28 & 0.90 \\
\hline $100-250$ & 1.80 & 0.13 & 1.82 & 1.20 \\
\hline $100-500$ & 1.93 & 0.13 & 2.35 & 1.60 \\
\hline $100-750$ & 2.25 & 0.12 & 3.85 & 2.80 \\
\hline
\end{tabular}

As the values for $m$ and $\mathrm{d} 0$ vary with suction, an average of these values is chosen, assuming the error associated with this assumption. Thus, $m=2,3$ and $\mathrm{d}_{0}=1,6$.

\subsection{Peak state}

As the soil response shows peak states, Eq. (8) requires adjusting parameter $\beta_{\mathrm{v}}$. This is done representing the exponential experimental curve " $\eta_{\mathrm{p}}$ " vs " $\psi$ s,p”. Figure 3 depicts both experimental and calculated response for all suction values. Interestingly, in this research the saturated tests showed strain hardening type stress-strain response with no distinct peak i.e., peak stress is equal to critical stress. Table 5 indicates parameters $M_{g}$ and $\beta_{\mathrm{v}}$ for all suctions but $\mathrm{s}=0$ (saturated case, no peak). However, during unsaturated testing the stress-strain curve showed distinct peak before reaching a critical stress. As the suction increases, so does the peak stress and hence a unified value has been considered, namely $\beta_{v}=2,0$ $(\mathrm{Mg}=2,0)$.

Table 5. Peak state parameters

\begin{tabular}{|c|c|c|}
\hline $\mathrm{s}(\mathrm{kPa})$ & $\mathrm{M}_{\mathrm{g}}(-)$ & $\beta_{\mathrm{v}}(-)$ \\
\hline 50 & 1.63 & 0.48 \\
\hline 250 & 1.68 & 1.00 \\
\hline 500 & 1.84 & 0.8 \\
\hline 750 & 2.20 & 1.9 \\
\hline calc & 1.42 & 2.0 \\
\hline
\end{tabular}




\subsection{Elasticity}

There are three elastic parameters involved in Eqns. (5), (6) and (7): $G_{\mathrm{es} 0}, K_{\mathrm{ev} 0}, v$. Any combination of two of them is a possible choice. Model performance with these two parameters should fit the initial slope of the experimental curve "q" vs " $\varepsilon_{\mathrm{s}}$ ". For the sake of brevity this fitting is not included. Final parameters are $\mathrm{G}_{\mathrm{es} 0}=80$ and $v=0.2$.

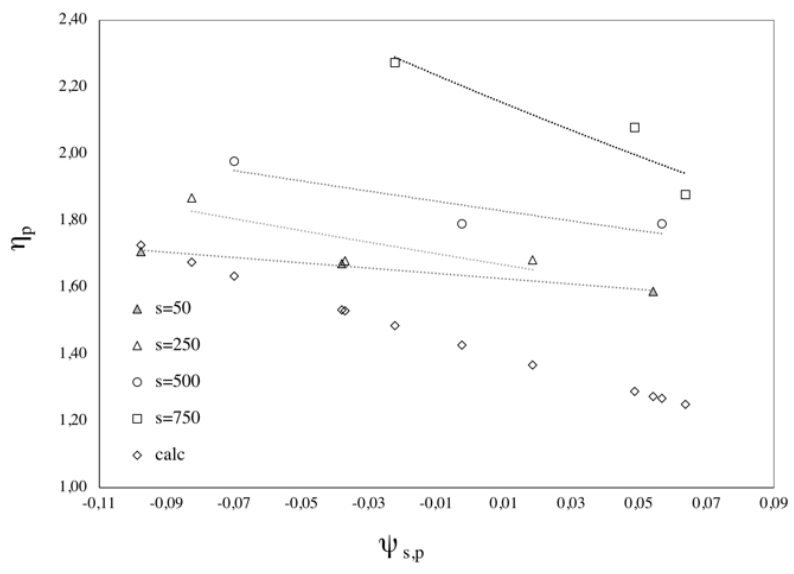

Fig. 3. Peak states for unsaturated conditions.

\subsection{Loading direction}

Calibration of loading directions constants, i.e. $h_{1}$ and $h_{2}$, is based on the hypothesis according to [17] that $\mathrm{M}_{\mathrm{f}} / \mathrm{M}_{\mathrm{g}} \approx \mathrm{D}_{\mathrm{r}}$, where $\mathrm{D}_{\mathrm{r}}$ is the relative density. Thus, adjusting " $\mathrm{M}_{\mathrm{f}} / \mathrm{M}_{\mathrm{g}}$ " vs " $\psi_{\mathrm{q}}$ " from Eq. (9), allows us to determine both $h_{1}$ and $h_{2}$. A value of 1.8 for $\beta$ has been assumed (Table 6).

\subsection{Bonding function}

Bonding function contains two material parameters: $a$ and $b$, according to Eq. (15). Calibration is achieved with experimental adjustment of Eq. (16) by plotting the bonding parameter " $\xi$ " vs the ratio of the effective stresses at CS, for unsaturated and saturated states. Table 6 shows the values for $a$ and $b$.

Table 6. Loading direction and bonding parameters

\begin{tabular}{|c|c|c|}
\hline \multicolumn{3}{|c|}{ Loading Direction Parameters } \\
\hline Parameter & $\mathrm{h}_{1}(-)$ & $\mathrm{h}_{2}(-)$ \\
\hline Value (unit) & 1.2 & 0.4 \\
\hline \multicolumn{3}{|c|}{ Bonding Parameters } \\
\hline Parameter & $\mathrm{a}(-)$ & $\mathrm{b}(-)$ \\
\hline Value (unit) & 1.8 & 0.5 \\
\hline
\end{tabular}

\subsection{Plastic modulus}

As explained in [18], calibration of plastic modulus $\mathrm{H}_{\mathrm{L}}$ from Eq. (11) can be accomplished by fitting the experimental (left) and calculated (right) terms of $\mathrm{Eq}$ (17). Vectors $\mathrm{n}=\left(\mathrm{n}_{\mathrm{v}}, \mathrm{n}_{\mathrm{s}}\right)$ and $\mathrm{n}_{\mathrm{g}}=\left(\mathrm{n}_{\mathrm{g}, \mathrm{s}}, \mathrm{n}_{\mathrm{g}, \mathrm{v}}\right)$ can be calculated from Eqns. (12) and (13) of [9].

$$
d q / d \varepsilon_{s} \approx \mathrm{H}_{\mathrm{L}} /\left[\mathrm{n}_{\mathrm{g}, \mathrm{s}}\left(\mathrm{n}_{\mathrm{v}} / 3+\mathrm{n}_{\mathrm{s}}\right)\right]
$$

Once $\mathrm{H}_{\mathrm{L}}$ is estimated, from Eq. (11) and reference [9], parameter $\mathrm{H}_{0}{ }^{\prime}$ can be determined. For the sake of brevity this fitting is not included. The plastic modulus chosen is $\mathrm{H}_{0}{ }^{\prime}=80$.

\subsection{Water retention curve}

Water retention curve (WRC), or Soil Water Characteristic Curve (SWCC), as expressed in Eq. (13) contains the following material parameters: $\Omega, \mathrm{a}_{\mathrm{w}}, \mathrm{n}, \mathrm{m}$ and $\mathrm{S}_{\mathrm{r} 0}$. To fit this WRC, an initial value of $\mathrm{e}=0.44$ is assumed. Table 7 shows the corresponding parameters obtained via adjustment of experimental SWRC.

Table 7. WRC parameters (from modified Fredlund \& Xing $[10,19])$.

\begin{tabular}{|c|c|c|c|c|c|}
\hline Parameter & $\Omega(-)$ & $\mathrm{a}_{\mathrm{w}}(-)$ & $\mathrm{n} \mathrm{(-)}$ & $\mathrm{m}(-)$ & $\mathrm{S}_{\mathrm{r} 0}(-)$ \\
\hline Value (unit) & 0.0 & 0.5 & 1.0 & 2.0 & 0.05 \\
\hline
\end{tabular}

\section{Model performance}

The MPZ constitutive model based on Generalized Plasticity (GP) is run with a driver capable of testing saturated and unsaturated states. Experimental data available [6] consists on constant-suction drained consolidated triaxial tests with three net stress levels $(100,200$ and $300 \mathrm{kPa})$ and five suction levels (0, 50, 250,500 and $750 \mathrm{kPa}$ ), as explained in section 2 .

Figures 4 and 5 represent deviatoric stress-strain response(a) and volumetric strains (b) for $s=0$, and 500 $\mathrm{kPa}$, respectively, and include both experimental and predicted (MPZ) curves together. Clearly, the MPZ model simulates the saturated response very well. Also, the MPZ constitutive model captures reasonably well the tendencies due to different net pressure and suction, with a unique set of constitutive parameters for $s=500 \mathrm{kPa}$ test. Clearly, the transition of compressive response for $\mathrm{s}=0$ to initial compression followed by dilatant type volumetric response for $\mathrm{s}=500 \mathrm{kPa}$ is smoothly captured by proposed MPZ model.

However, some departures from experimental results should be noted. Peak states for suction of $500 \mathrm{kPa}$ are not reproduced. This is noticeable especially for higher suction and net pressures values. Regarding volumetric behaviour, constitutive model shows a slight tendency to increase the dilatant response, in comparison with the experimental volumetric strains. 

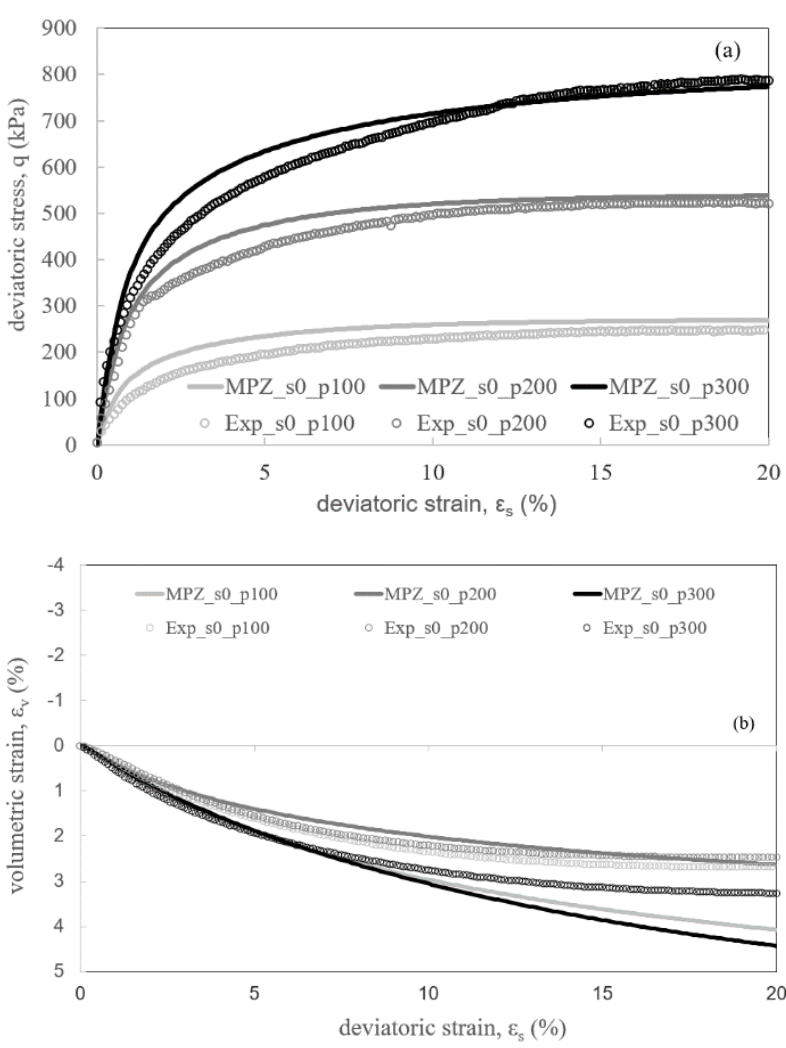

Fig. 4. Stress-strain(a) and volumetric strains (b), s=0 kPa.
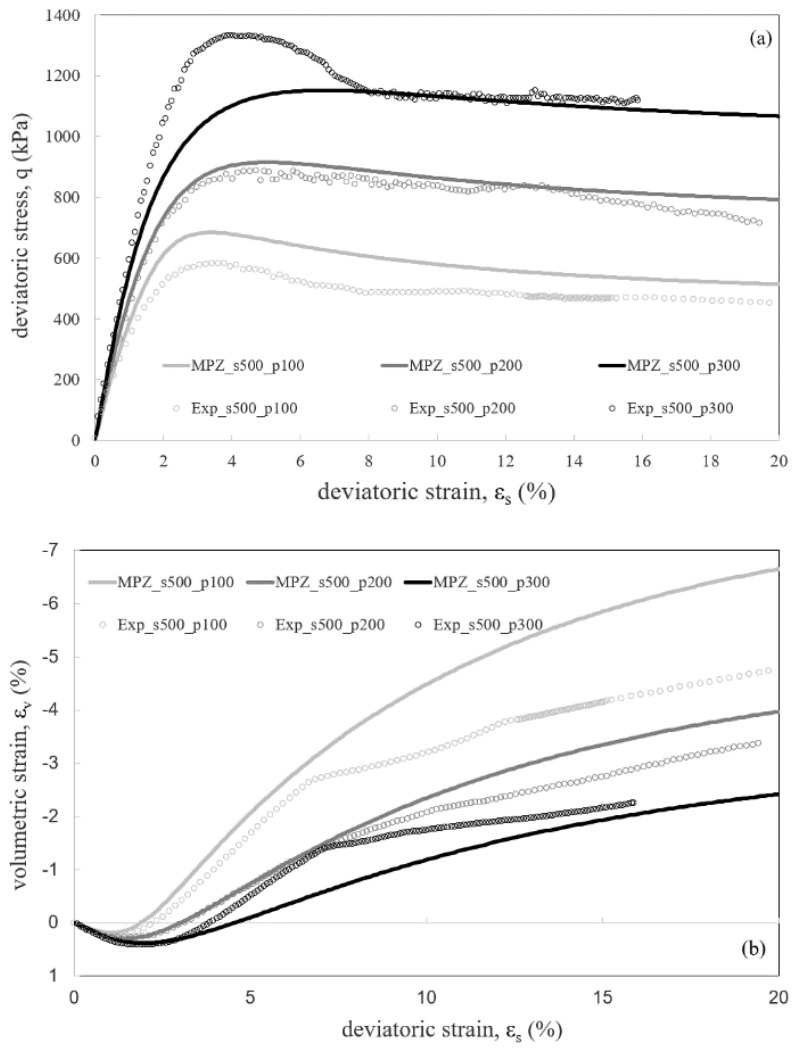

Fig. 5. Stress-strain(a) and volumetric strains (b), s=500 kPa.

\section{Conclusions}

A procedure for calibrating the parameters of the MPZ constitutive model, a type of generalized constitutive model, is presented. This calibration is done for a set of consolidated drained triaxial tests, with three different net stress levels and five different suction levels including the saturated case. In some cases, differences between saturated and unsaturated states arise, as in critical state parameters $e_{a}$ and $\lambda$. In some others, as in dilatancy and peak states, suction level affects the response and a compromise solution has been reached. Criterium has been to maintain a unique set of parameters for all states of density, pressure and suction. However, in future research, the effect of suction on peak and dilatancy must be further clarified. Besides, a quantification of error induced by calibration should be introduced, to be able to measure its quality.

The constitutive model adopted performs reasonably well, given the different net pressures and suctions that the set of experimental tests comprises. However, peak states associated with high suctions $(\mathrm{s}=500 \mathrm{kPa})$ are not accurately modelled. This requires further research and improvement of the model.

\section{References}

1. E.E. Alonso, A. Gens, A.A. Josa, Géotechnique. 40,3 (405-430), (1990).

2. A. Anandarajah, Y.F. Dafalias, J. Eng. Mech., 112, 12, (1292-1318), (1986).

3. H.I. Ling, D. Yue, V.N. Kaliakin, N.J. Themelis, J. Eng. Mech, 128, 7, (748-758), (2002).

4. J.P. Bardet, J. Eng. Mech. 112, 11, (1198-1217), (1986).

5. Z.L. Wang, Y.F. Dafalias, C.K. Shen, J. Eng. Mech. 116, 5, (983-1001), (1990)

6. U.D. Patil, L.R. Hoyos, M.M. Morvan, A.J. Puppala, Int. J. for Num. and Analyt. Methods in Geomech, 35, 12, (1347-1362), (2011).

7. U.D. Patil, L.R. Hoyos, A.J. Puppala, Int. J. Geomechanics, 16, 6 (2016)

8. M. Pastor, O.C. Zienkiewicz, A.H.C. Chan, Int. J. for Num. and Analyt. Methods in Geomech, 14, 3, (151-190), (1990).

9. D. Manzanal, M. Pastor, J.A. Fernández Merodo, Int. J. for Num. and Analyt. Methods in Geomech, 35, 12, (1347-1362), (2011).

10. D. Manzanal, M. Pastor, J.A. Fernández Merodo, Int. J. for Num. and Analyt. Methods in Geomech, 35, 18, (1899-1917), (2011).

11. M. Pastor, Comp. and Geot., 11, 3, (173-208), (1991).

12. M. Pastor, O.C. Zienkiewicz, G-D. Xu, J. Peraire, Modern Approaches to Plasticity (Ed. D. Kolymbas), (469-192), (1993).

13. D. Fredlung, A. Xing, Can. Geot. J., 31, (521-532), (1994).

14. D. Gallipoli, S.J. Wheeler, M. Karstunen, Géotechnique, 53, 1, 105-112, (2003).

15. D. Gallipoli, A. Gens, R. Sharma, J. Vaunat, Géotechnique, 53, 1, 123-135, (2003). 
16. X.S. Li, J. of Geot. And Geoenv. Eng, 123, 7, (609616), (1997).

17. O.C. Zienkiewicz, A.H.C. Chan, M. Pastor, B.A. Schrefler and T. Shiomi, Comp. Geom., (Wiley, New York, 1999)

18. D. Manzanal, Ph.D. Thesis, School of Civil Engineering, Polytechnic University of Madrid, (2008)

19. D.Manzanal, M. Pastor, J.A. Fernández Merodo, P. Mira. Computer Modelling in Engineering and Science CMES, 55, 3, 293-317, (2010) 